\title{
Exercise and the promotion of health
}

\section{By P. H. Fentem, Department of Physiology and Pharmacology, Queen's Medical Centre, University of Nottingham, Clifton Boulevard, Nottingham $\mathrm{NG}_{7}{ }_{2} \mathrm{UH}$}

Evidence is growing that increased levels of regular physical exercise can contribute to health and well-being. This evidence is now regarded as sufficient to justify health education programmes directed at the promotion of positive attitudes towards exercise and participation by all age-groups. Those findings which suggest that exercise may have a role in limiting heart disease have aroused the greatest interest but there is other evidence to indicate that the benefits are more extensive. These benefits may be usefully considered under three headings: the enhancement of normal health, the amelioration of the effects of chronic disease and age, and the prevention of disease.

\section{The enhancement of normal health}

Sedentary individuals have a limited tolerance for physical effort and they find that modest physical work provokes discomfort. This is not too surprising if the energy cost of performing everyday activities is set against the maximum work capacity of such sedentary subjects. Bruce (1978) reported the maximum work capacity of groups of men of different ages residing in Seattle, USA. He found that a group of 45-54-year-old sedentary men in normal health had a maximum oxygen consumption of 33 (SE 5) $\mathrm{ml} \mathrm{O}_{2} / \mathrm{kg}$ per min. Walking at $6.4 \mathrm{~km} / \mathrm{h}(4 \mathrm{miles} / \mathrm{h})$ costs about $17 \mathrm{ml} \mathrm{O} / \mathrm{kg}$ per $\mathrm{h}$ and walking at $4.8 \mathrm{~km} / \mathrm{h}$ (3 miles/h) uphill (I in 7 ) or against a strong wind, $27 \mathrm{ml} \mathrm{O} / \mathrm{kg}$ per min; thus these activities require approximately 52 and $82 \%$ respectively of the mean maximum capacity of the group. The lower intensity of effort is sufficient to cause lactate accumulation and this explains why these subjects would barely have the capacity to take a long brisk walk on level ground without fatigue. The higher intensity is likely to provoke the symptoms associated with severe exertion. The greater the percentage of an individual's maximum capacity that has to be used to perform a bout of physical work, the greater the physical stress. When this exceeds $50-60 \%$ of the maximum capacity the sympathetic neural drive to the heart and blood vessels rises and the levels of circulating catecholamines are elevated. If these levels of work capacity are to be generally found among the middle-aged, which seem likely, then they are limiting and likely to increase the risk of occasional and unavoidable bouts of heavy exertion.

When sedentary individuals assume a more active lifestyle and persist with the change in the amount of exercise in which they engage they find that in a matter of a few weeks exercise is less of an effort. They become aware of an increase in their capacity for work, that is they can work harder, exert themselves for longer and do so with less fatigue. Saltin et al. (1968) demonstrated in a classical experiment the 
relation between maximum work capacity and levels of habitual physical activity. They studied the measurements of maximum $\mathrm{O}_{2}$ uptake of three subjects who were habitually sedentary. They found that maximum capacity for work fell by one-third following bed rest for $20 \mathrm{~d}$ and was greater by one-quarter after training for $50 \mathrm{~d}$.

Work performed by various Scandinavian research groups has demonstrated the importance of the metabolic adaptations which occur in skeletal muscles as a result of a maintained increase in regular exercise. The effects are specific to the muscles used and the way in which they are used. With increased exercise the working muscle cells show an increase in the maximum activities of enzymes in both cytosol and mitochondria, changes which have been shown to reflect increases in the maximum capacities of the major metabolic pathways to release energy (Newsholme et al. I980). There are parallel increases in both the size and number of mitochondria. Andersen \& Henriksson (1977) took samples of muscle by needle biopsy from volunteers who had trained for 8 weeks and showed these increases in enzymic activity and metabolic capacity. They also found that the density of the capillaries supplying the muscle cells was greater than before the training.

The overall biochemical response is altered as a consequence of changes in metabolic capacities. Henriksson (1977) describes the results of his use of the experimental design which involves training only one leg of relatively unfit volunteers. The same individual has both a trained and untrained leg which can be compared. In these experiments it could be shown that for a given intensity of one-legged exercise the untrained muscles released lactate and utilized carbohydrate but little fat; the trained muscles oxidized more fat and less carbohydrate but did not release any lactate.

These adaptations of muscle metabolism lead to an improvement in $\mathrm{O}_{2}$ extraction and a consequent reduction in the blood flow to the muscle. They are the essential basis of fitness for endurance exercise. The extent to which the initial improvement in cardiovascular function is secondary to these changes and the supporting evidence has been reviewed by Saltin \& Rowell ( 1980 ).

The consequences of biochemical and cardiovascular adaptations to training are that maximum work capacity and endurance improve and fatigue is reduced. Thus training extends the range of physical activity in which the individual may safely and comfortably participate.

\section{Amelioration of the effects of disease: the physiological basis for exercising cardiac patients}

When healthy subjects train their heart rate is slower at rest than before training and for any given level of work it rises but to lower levels than before training, whereas the cardiac output at rest is similar to that before training and the increase with exercise is also of a similar magnitude. This is beneficial in two ways. Because trained muscles require a smaller blood flow and hence a smaller proportion of the total cardiac output, the blood flow is not directed towards the muscles at the expense of the supply to the intestines and kidneys until the subject reaches a much 
higher level of exertion than formerly. This is another way in which the general physiological disturbance for any level of exercise is less severe. The second benefit is that the reduction in heart rate reduces myocardial work for any level of exercise. This is so because of the three determinants of myocardiac energy expenditure, heart rate, arterial blood pressure and myocardial contractile state; heart rate is especially important. Thus the effect of training is not so much to improve the heart's performance as to spare it by reducing the amount of work it has to perform. The additional benefit is that more exercise can be taken than before. These changes are observed to occur in patients with cardiac disease and represent the physiological basis of cardiac rehabilitation. Cardiac patients obtain yet another benefit from training; there is a reduction in both heart rate and cardiac output at a particular exercise intensity reducing myocardial work even further (Clausen, I977).

\section{The prevention of disease: the effect of regular exercise on the natural history of coronary artery disease}

A key issue is whether increased levels of exercise can be expected to 'prevent' coronary artery disease or at least modify the natural history of the disease and delay the occurrence of its complications, angina, heart attack and sudden death. Whenever national committees or individual authors have reviewed the evidence during the last decade they have usually concluded that there is an established association between high levels of physical activity and a low incidence of coronary heart disease which may be causal. Since the pathological changes may progress steadily for 20 or 30 years before clinical symptoms are apparent the evidence is specially difficult to collect. The search depends on having meaningful descriptions of the lifestyle which individuals have followed for a decade or more as well as requiring the study of several thousands of individuals and the reliable recording of illness and cause of death.

Morris's (Morris et al. 1973) longitudinal study of I8 000 British middle-aged male civil servants has provided important evidence that participation in vigorous exercise during leisure time is beneficial. These men, all in sedentary jobs, entered the study in 1968 by completing a detailed account of the way they had spent two out of the three preceding days. The diaries were analysed for the time spent in vigourous exercise (VE) defined for the purpose of the analysis as exercise costing more than $31.4 \mathrm{~kJ} / \mathrm{h}(7.5 \mathrm{kcal} / \mathrm{h})$. When, after 4 years, the first report was prepared (Morris et al. 1973) those who said that they had engaged in VE during their leisure time suffered a heart attack with only one-third the frequency of matched controls who were inactive. When, in 1978 , the mortality for a subgroup from coronary heart disease was analysed as part of a further examination of the fate of a one-fifth sample, the death rate from coronary heart disease was four times lower in those who were physically active. Only eight of the 777 in the sample who had engaged in VE at the beginning of the study had died of cardiovascular disease, whereas thirty-four would have died had they experienced the same mortality rate as those who did not engage in VE (Chave et al. 1978). 
Similar studies have been undertaken in the United States. Paffenbarger (Paffenbarger et al. 1978) collected information on the exercise content of the lives of groups of former students of Harvard and the University of Pennsylvania. Men who reported climbing fifty steps/d appeared to have a $20 \%$ lower risk of coronary heart disease (CHD) than men who climbed less. Those who walked more than 0.8 $\mathrm{km}(0.5 \mathrm{mile})$ each day on their journey to work had a $21 \%$ lower risk. The study is of some significance because the authors found some benefit if those studied had an extra energy expenditure of no more than $8370 \mathrm{~kJ}(2000 \mathrm{kcal}) /$ week. This is a modest expenditure of energy on exercise and represents a level which could be achieved by many with only small changes in customary lifestyle.

The same investigator working with Hale (Paffenbarger \& Hale, 1975) had previously shown that very much higher levels of exertion at work appeared necessary to have a significant influence. In a study of dockers in San Francisco, followed for 22 years, men who had jobs requiring repeated bursts of high energy output had a death rate from CHD only half that of the men in jobs requiring a medium or low energy output. The level of 'high energy output' was an extra 33 $\mathrm{MJ}(8000 \mathrm{kcal}) /$ week which was more than three times that common in the general population.

Attempts to identify the mechanism by which exercise might reduce the incidence of the disease have been directed towards assessing its role in modifying the already-identified major 'risk factors' or the critical pathological mechanisms. Paffenbarger et al. ( $\mathrm{I} 8_{3}$ ) have recently reported their study of the relation between the lifestyle of college students and the subsequent development of hypertension. They demonstrated that former students who did not engage in vigorous leisure activity ran a greater risk of developing hypertension. Regular exercise is also effective when hypertension has already developed; it leads to a useful reduction in blood pressure of about $10 \mathrm{~mm} \mathrm{Hg}$ when the hypertension is moderate. It does not benefit severe hypertension.

The handling of cholesterol by the body is also improved by exercise and it is tempting to believe that this is the mechanism by which vigorous exercise mediates its protective role. Coronary artery disease develops because increasing amounts of fat and cholesterol are deposited in the wall of the coronary arteries. This is coronary atherosclerosis.

Cholesterol is transported between organs and tissues by the blood lipoproteins. The low-density lipoproteins (LDL) are responsible for depositing cholesterol in cells including the cells lining blood vessels. The high-density lipoproteins (HDL) are of special interest because they have been shown to transport cholesterol out of the arterial wall fibroblasts and endothelial cells. Thus they have a potential role for reducing the fat and cholesterol in arterial walls. In several studies, including the Tromso study undertaken in Norway (Miller et al. 1977), high levels of HDL have been shown to be related to a low incidence of CHD whereas low levels of the same lipoproteins were associated with rapidly-advancing disease. Conversely high levels of LDL are associated with a high risk of rapid advancement of disease of the coronary vessels. 
Several studies have demonstrated that an exercise programme based on running or jogging will lead to an elevation of HDL levels (Wood \& Haskell, 1979). But not every study has confirmed this. A recent report from Stanford University (Wood \& Haskell, 1983) has been based on a I-year randomized controlled study. It suggests that the threshold running distance which will raise HDL is about 13 $\mathrm{km}$ ( 8 miles)/week. If this can be confirmed it is an important observation since this is a threshold which is easily attainable by most young and middle-aged.

Given that the composition of the diet also influences the blood levels of the lipoproteins, it is of some significance that the lipoproteins change in a favourable manner even though the dietary intake is greater. Indeed, those who exercise take more fat; they appear to increase their total food intake by taking more of everything rather than by selectively changing the composition of their diet (Wood \& Haskell, 1982).

Exercise has other favourable effects. It is a valuable adjunct to dietary control in the prevention and treatment of obesity. In man as well as in experimental animals it has been shown to improve glucose tolerance and to reduce the plasma insulin concentrations in response to a glucose load (Bjorntorp et al. 1972; Berger et al. 1979). It is still unclear whether exercise is capable of so modifying carbohydrate metabolism that it modifies the natural history of late-onset diabetes and the development of its complications. Its benefits are of special importance to the elderly. The possibility has been raised by recent studies that it can ameliorate the progress of osteoporosis.

The evidence does appear sufficient to justify the active promotion of exercise for its benefits to health. The hope must be that any changes in national leisure habits and their effects can be monitored carefully and that resources for research in this field grow to match the importance of the topic.

\section{REFERENCES}

Anderson, P. \& Henriksson, J. (1977). Fournal of Physiology 270, 677-690.

Berger, M., Kemmer, F. W. \& Becker, K. (1979). Diabetologia 16, I 79-184.

Bjorntorp, P., Fahten, M. \& Grimby, G. (1972). Metabolism 21, 1037-1044.

Bruce, R. A. (1 978). Report of Seattle Heart Watch Studies.

Chave, S. P. W., Morris, J. N., Moss, S. \& Semmence, A. M. (1978). Journal of Epidemiology and Community Health 32, 239-243.

Clausen, J. P. (1977). Physiological Reviews 57, 779-81 5 .

Henriksson, J. (1977). Fournal of Physiology 270, 661-675.

Miller, N. E., Forde, D. H., Thelle, D. S. \& Mjos, O. D. (1977). Lancet i, 965-968.

Morris, J. N., Chave, S. P. W., Adam, C., Siray, C. \& Epstein, L. (1973). Lancet i, 333-339.

Newsholme, E. A., Crabtree, B. \& Zammit, V. A. (1980). Ciba Foundation Symposium 73, $245^{-258 .}$

Paffenbarger, R. S. Jr, \& Hale, W. E. (1975). New England fournal of Medicine 292, 545-550.

Paffenbarger, R. S. Jr, Wing, A. L. \& Hyde, R. T. (r 978). American Yournal of Epidemiology 108, $162-175$.

Paffenbarger, R. S. Jr, Wing, A. L., Hyde, R. T. \& Jung, D. L. (1983). American fournal of Epidemiology $117,245^{-257}$.

Saltin, B., Blomquist, G., Mitchell, J. H., Johnson, R. L. Jr, Wildenthal, K. \& Chapman, C. B. ( 1968 ). Circulation 38 Suppl., $\mathrm{r}-55$. 
Saltin, B. \& Rowell, L. B. (1980). Federation Proceedings 39, 1506-1 513.

Wood, P. D. \& Haskell, W. L. (1979). Lipids 14, 417-427.

Wood, P. D. \& Haskell, W. L. (1982). In Diet and Exercise: Synergism in Health Maintenance, pp. $39-47$ [P. L. White and T. Mohdicka, editors]. Chicago: American Associates.

Wood, P. D. \& Haskell, W. L. (1983). Metabolism 32, 31-39. 